\title{
Blue Photoluminescence N-Substituted Poly(4H-benzo[def]carbazole)s
}

\author{
ZhongMin Geng ${ }^{1,2}$, Kosuke Shibasaki ${ }^{1,2}$, Masashi Kijima ${ }^{2,3,4, *}$
}

\begin{abstract}
${ }^{1}$ Institute of Materials Science, Graduate School of Pure and Applied Sciences, University of Tsukuba, 1-1-1 Tennodai, Tsukuba, Ibaraki 305-8573, Japan

${ }^{2}$ Tsukuba Research Center for Interdisciplinary Materials Science, University of Tsukuba, 1-1-1 Tennodai, Tsukuba, Ibaraki 305-8573, Japan

${ }^{3}$ Division of Materials Science, Faculty of Pure and Applied Sciences, University of Tsukuba, 1-1-1 Tennodai, Tsukuba, Ibaraki 305-8573, Japan

${ }^{4}$ Algae Biomass Energy System Research and Development Center, University of Tsukuba, 1-1-1 Tennodai, Tsukuba, Ibaraki 305-8573, Japan
\end{abstract}

Correspondence to: M. Kijima (kijima@ims.tsukuba.ac.jp); Fax.: +81 298534490

\begin{abstract}
N-Alkyl and N-phenyl substituted poly(carbazole)s having a 4,5-ethenylene bridge, poly( $4 H$-benzo[def]carbazole)s, were newly synthesized. Poly(carbazole)s having a 4,5-ethylene bridge were also synthesized for comparison. They were prepared from corresponding dibromo monomers by $\mathrm{Ni}(0)$-catalyzed Yamamoto polycondensation. All the polymers had good solubility in common organic solvents, enough high molecular weights to make thin films, and good thermal stability showing about $400{ }^{\circ} \mathrm{C}$ of temperature at $5 \mathrm{wt} \%$ loss in TGA. The band gaps of these polymers were in the range of $2.77-3.15 \mathrm{eV}$ which were appropriate for bluish light emissions. The absorption and emission maxima of these polymers in $\mathrm{CHCl}_{3}$ were in the ranges of 361-396 and 419-456 nm, respectively. These polymers showed good fluorescence quantum efficiencies in $\mathrm{CHCl}_{3}$. The energy levels of highest occupied molecular orbital of the poly(benzocarbazole)s were shallower than those of corresponding 4,5-ethylene bridged poly(carbazole)s.
\end{abstract}

Keywords: Conjugated polymer, Carbazole, Photoluminescence

\section{Introduction}

The polymeric light-emitting diodes (PLEDs) have been investigated to be practically used as display devices, because they can be fabricated with simple coating techniques and show tolerable emitting efficiencies. [1]. Among three basic colors of blue, green, and red for full-color displays, development of high-efficiency blue-light-emitting materials is important. Because the short-wavelength emission can serve as an excitation source for emissions over the whole visible range [2]. Since the first report on blue PLEDs device which was fabricated with poly ( $p$-phenylene) (PPP) in 1992 [3], a large number of materials for blue-light-emitting have been developed [4-8]. Among the blue-light-emitting polymers, fluorene-based conjugated polymers have been recognized as a promising class, because they are good processable materials and show rarely high 
fluorescent performances in the solid state [9, 10]. Unfortunately, polyfluorene-based PLEDs have usually emitted impure blue colors due to emissions from contaminates such as excimers and keto-defects in addition to principal emission from $\beta$-phase [11]. Since early in this century, poly(2,7-carbazole)s regarded as a strained planner poly(4,4'-biphenylylene) with an imino-bridge have been considered as a new candidate for blue light emitting materials comparable to the fluorene-based polymers, because they have wide band gaps appropriate for blue light emissions, sharp emission bands in the solid film state, and smaller ionization potentials compared to polyfluorenes [12-16].

In this paper, several new poly(carbazole)s for stable light emitting are attempted to synthesize by bridging a carbazole $(\mathbf{C z})$ unit with 4,5-ethenylene to construct the benzo[def]carbazole $(\mathbf{B C z})$ structure as shown in Fig. 1. Dehalogenative polyconsensation of 2,6-dibrominated and 1,7-dibrominated $\mathbf{B C z}$ monomers gave corresponding poly(benzo[def]carbazole)s (PBCz). In parallel, 4,5-ethylene bridged polycarbazoles, poly(8,9-dihydro-2,6-benzo[def] carbazole)s (PECz), were also synthesized from the precursor derivatives of the ethylene bridged carbazoles $(\mathbf{E C z})$ for comparison. Basic properties of these polymers were compared with those of poly(2,7-carbazole $) \mathrm{s}$ and poly(3,6-carbazole)s.

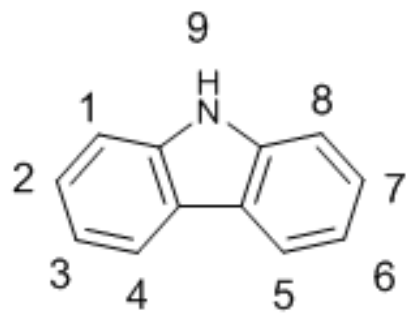

$\mathrm{Cz}$

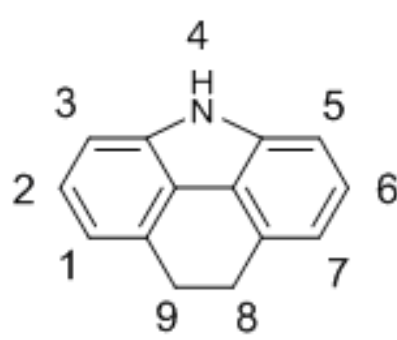

$\mathrm{ECz}$

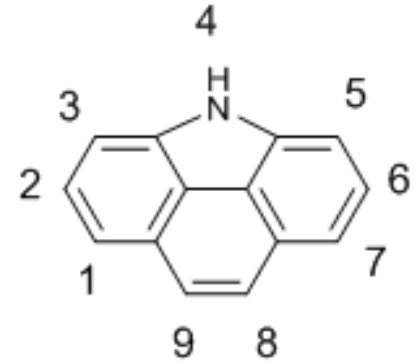

$\mathrm{BCz}$

Fig. 1 The structures and numbering system of $\mathbf{C z}, \mathbf{E C z}$ and $\mathbf{B C z}$

\section{Experimental}

\subsection{Materials}

1-Decylundecyl-4-methylbenzenesulfonate and 1-(1-decylundecyloxy)-4-iodobenzene were synthesized according to the procedures reported previously [17, 18]. 2,6-Dibrominated $\mathbf{E C z}(3)$ was synthesized by reductive ring closure of $\mathbf{2}$ that was prepared by nitration of $\mathbf{1}$ according to the procedures reported previously (Scheme 1 see Supporting information ) [19]. Reagents and solvents were purchased from Kanto Chemical, Tokyo Chemical Industry, Aldrich and Nacalai Tesque Inc. Dimethylformamide (DMF) and benzene distilled after drying with $\mathrm{CaH}_{2}$ were stored under an argon atmosphere. Tetrahydrofuran (THF) distilled after drying with sodium was stored under an argon atmosphere. The other solvents and all commercially available reagents were used without further purification. 


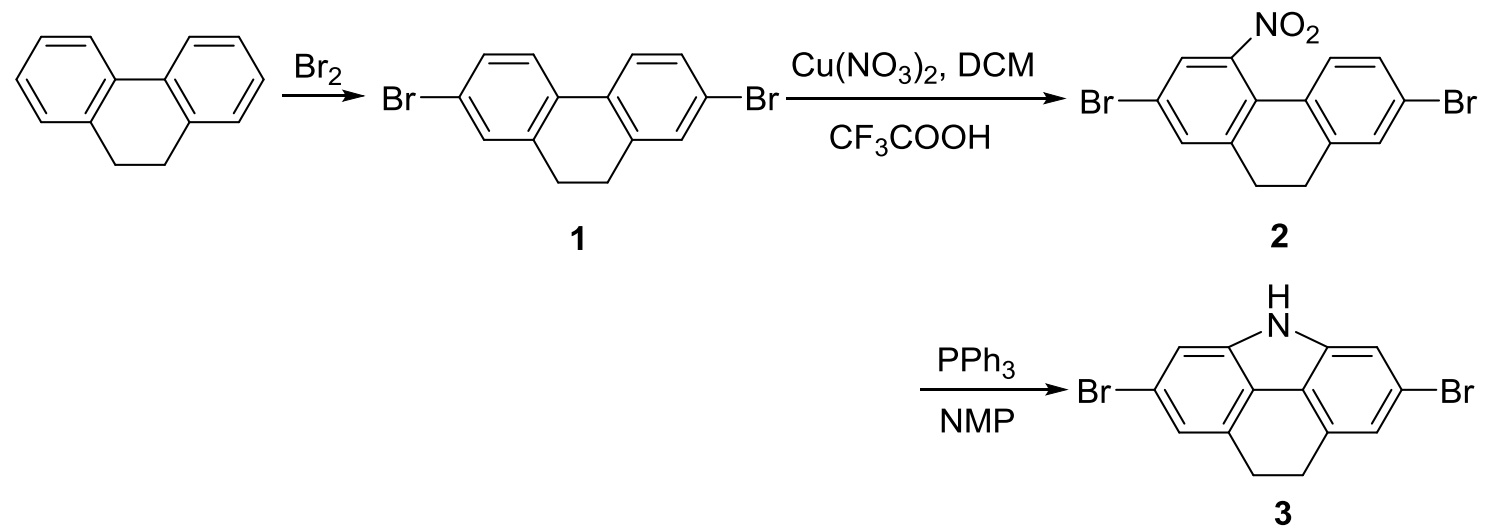

Scheme 1. Synthetic route of 2,6-dibromo-8,9-dihydrobenzo[def] carbazole

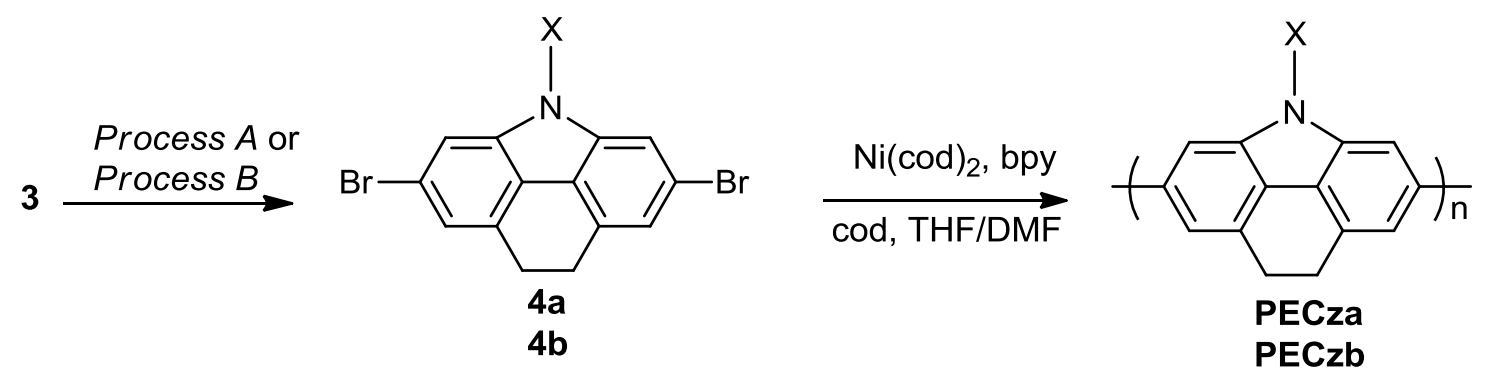

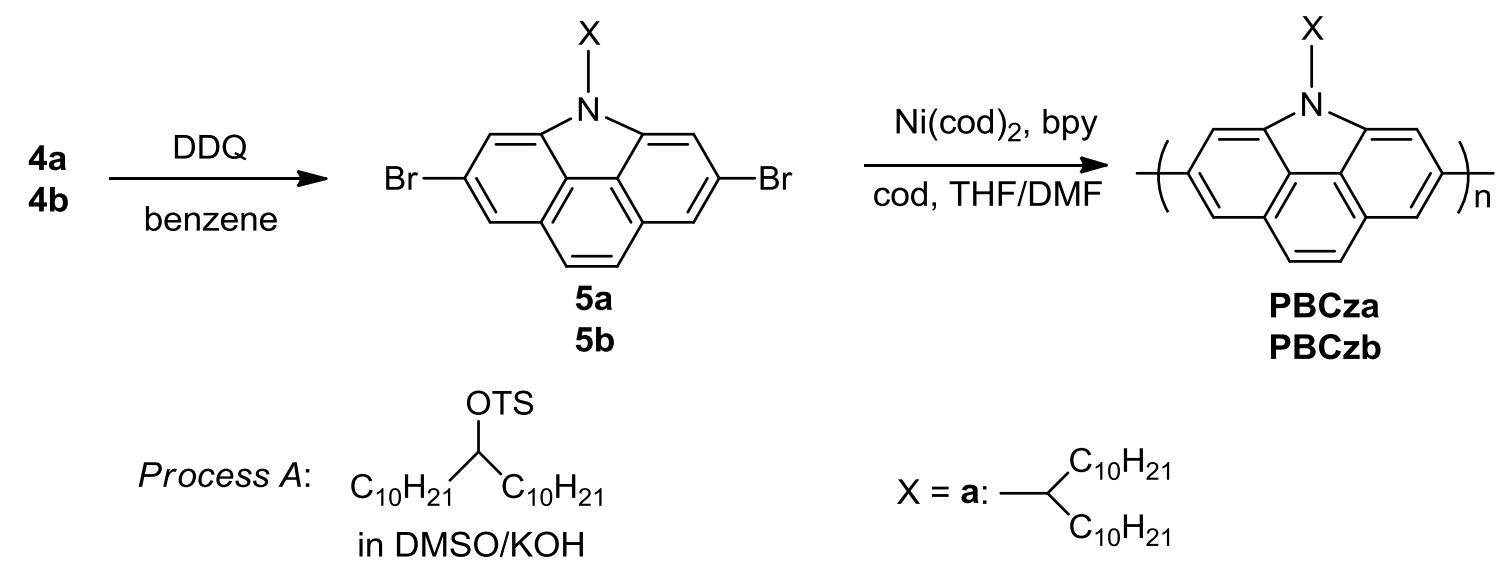

Process $\mathrm{B}$ : Cul, $\mathrm{K}_{3} \mathrm{PO}_{3}$ in THF/

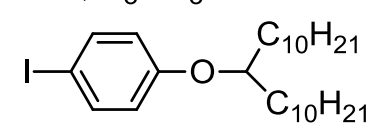

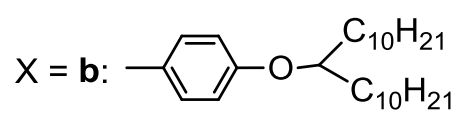

Scheme 2. Synthetic routes of PECz and $\mathbf{P B C z}$ 


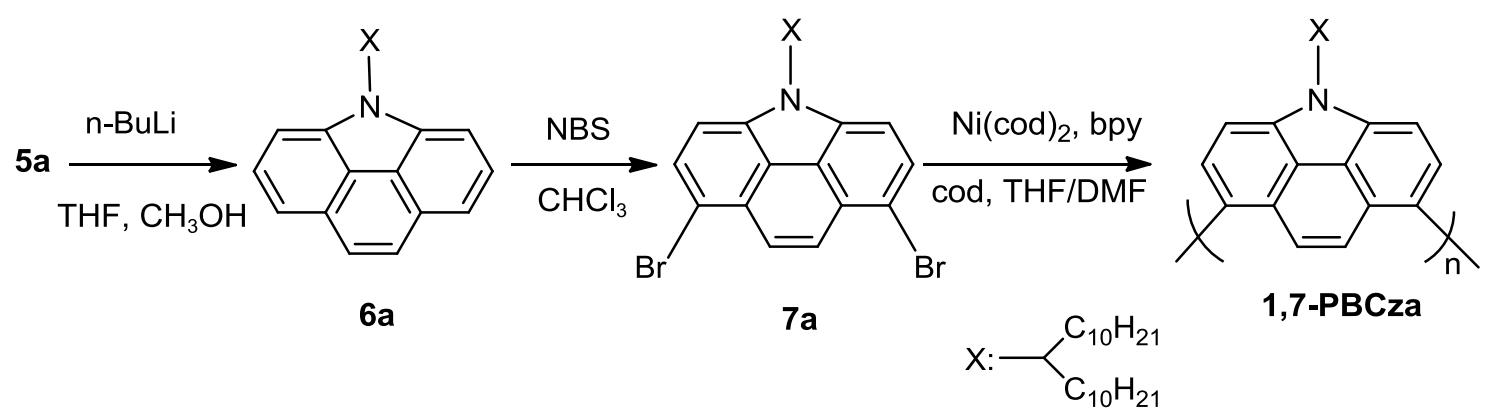

Scheme 3. Synthetic route of 1,7-PBCza

2,6-Dibromo-N-(1-decylundecyl)-8,9-dihydrobenzo[def] carbazole (4a). To suspension of $\mathbf{3}$ (2 g, 5.7 $\mathrm{mmol}$ ) and potassium hydroxide $(1.46 \mathrm{~g}, 26 \mathrm{mmol})$ in dimethyl sulfoxide (DMSO) (25 $\mathrm{mL})$ was added dropwise solution of 1-decylundecyl-4-methylbenzenesulfonate (2.65 g, $5.7 \mathrm{mmol})$ in DMSO $(14 \mathrm{~mL})$ under argon. The mixture was stirred at room temperature for $6 \mathrm{~h}$. Then the mixture was poured into water. After extraction with dichloromethane, drying over $\mathrm{MgSO}_{4}$ and evaporation of the solvent, the crude product was purified by column chromatography (silica gel, dichloromethane/hexane, 1:1, as an eluent), giving yellow oil $(2.27 \mathrm{~g}, 62 \%) .{ }^{1} \mathrm{H}$ NMR $(400 \mathrm{MHz}$, $\left.\mathrm{CDCl}_{3}\right) \delta[\mathrm{ppm}]: 7.34(\mathrm{~s}, 2 \mathrm{H}), 7.11(\mathrm{~s}, 2 \mathrm{H}), 4.24(\mathrm{~m}, 1 \mathrm{H}), 3.28(\mathrm{~s}, 4 \mathrm{H}), 2.13-2.09(\mathrm{~m}, 2 \mathrm{H}), 1.89-1.85$ $(\mathrm{m}, 2 \mathrm{H}), 1.28-1.14(\mathrm{~m}, 32 \mathrm{H}), 0.88-0.84(\mathrm{~m}, 6 \mathrm{H}) ;{ }^{13} \mathrm{C} \mathrm{NMR}\left(100 \mathrm{MHz}, \mathrm{CDCl}_{3}\right) \delta[\mathrm{ppm}]: 138.6$, 131.4, 120.8, 119.9, 120.0, 111.4, 57.6, 34.0, 31.8, 29.6, 29.5, 29.4, 29.3, 29.2, 26.1, 22.6, 14.1. Calcd for $\mathrm{C}_{35} \mathrm{H}_{51} \mathrm{Br}_{2} \mathrm{~N}$ (645.61): C, 65.11; H, 7.96; N, 2.17. Found: C, 65.42; H, 8.21; N, 2.20.

2,6-Dibromo-N-(p-(1-decylundecyloxy)phenyl)-8,9-dihydrobenzo[def]carbazole (4b). Suspension of potassium phosphate $(0.8 \mathrm{~g}, 3.7 \mathrm{mmol}), 3$ (0.66 g, $1.9 \mathrm{mmol})$, CuI (3.6 mg, $1.9 \mathrm{mmol})$, 1-(1-decylundecyloxy)-4-iodobenzene $(4.37 \mathrm{~g}, 8.5 \mathrm{mmol})$ and trans-1,2-cyclohexanediamine $(0.011$ $\mathrm{mL}, 0.094 \mathrm{mmol})$ in THF ( $3 \mathrm{~mL}$ ) was stirred at $65{ }^{\circ} \mathrm{C}$ for 3 days. After cooling to room temperature, the mixture was poured into water. After extraction with dichloromethane, drying over $\mathrm{MgSO}_{4}$ and evaporation of the solvent, the crude product was purified by column chromatography (silica gel, hexane as an eluent) to give a white solid $(1.1 \mathrm{~g}, 60 \%) .{ }^{1} \mathrm{H} \mathrm{NMR}\left(400 \mathrm{MHz}, \mathrm{CDCl}_{3}\right) \delta$ [ppm]: 7.43 $(\mathrm{d}, \mathrm{J}=6.8 \mathrm{~Hz} 2 \mathrm{H}), 7.39(\mathrm{~s}, 2 \mathrm{H}), 7.18(\mathrm{~s}, 2 \mathrm{H}), 7.06(\mathrm{~d}, \mathrm{~J}=8.0 \mathrm{~Hz} 2 \mathrm{H}), 4.28(\mathrm{~m}, 1 \mathrm{H}), 3.32(\mathrm{~s}, 4 \mathrm{H})$, 1.73-1.67 (m, 4H), 1.43-1.27 (m, 32H), 0.90-0.86 (m, 6H); $\left.{ }^{13} \mathrm{C} \mathrm{NMR} \mathrm{(100} \mathrm{MHz,} \mathrm{CDCl}_{3}\right) \delta[\mathrm{ppm}]:$ 157.7, 139.0, 131.3, 130.0, 126.1, 126.0, 121.2, 121.1, 120.5, 116.9, 111.2, 78.5, 33.9, 31.9, 31.5, 29.7, 29.6, 29.3, 26.1, 25.4, 22.7, 22.6, 14.1. Calcd for $\mathrm{C}_{41} \mathrm{H}_{55} \mathrm{Br}_{2} \mathrm{NO}$ (737.71): C, 66.65; H, 7.52; $\mathrm{N}$, 1.90. Found: C, 66.31; H, 7.68; N, 1.97 .

2,6-Dibromo-4-(1-decylundecyl)-4H-benzo[def]carbazole (5a). A mixture of $4 \mathbf{4 a}(0.5 \mathrm{~g}, 0.78 \mathrm{mmol})$ and 2,3-dichloro-5,6-dicyano-1,4-benzoquinone (DDQ) (0.42 g, $1.8 \mathrm{mmol})$ in benzene (77 $\mathrm{mL})$ was refluxed for $8 \mathrm{~h}$ under a $\mathrm{N}_{2}$ atmosphere. After cooling to room temperature, the mixture was poured into water. After extraction with dichloromethane, drying over $\mathrm{MgSO}_{4}$ and evaporation of the solvent, the crude product was purified by column chromatography (silica gel, hexane as an eluent) to give a white solid $(0.42 \mathrm{~g}, 85 \%) .{ }^{1} \mathrm{H}$ NMR $\left(400 \mathrm{MHz}, \mathrm{CDCl}_{3}\right) \delta[\mathrm{ppm}]: 7.96(\mathrm{~s}, 2 \mathrm{H}), 7.90(\mathrm{~s}, 2 \mathrm{H})$, $7.66(\mathrm{~s}, 2 \mathrm{H}), 4.52(\mathrm{~m}, 1 \mathrm{H}), 2.29-2.25(\mathrm{~m}, 2 \mathrm{H}), 2.01-1.95(\mathrm{~m}, 2 \mathrm{H}), 1.25-1.11(\mathrm{~m}, 32 \mathrm{H}), 0.89-0.83(\mathrm{~m}$, $6 \mathrm{H}) .{ }^{13} \mathrm{C}$ NMR $\left(100 \mathrm{MHz}, \mathrm{CDCl}_{3}\right) \delta[\mathrm{ppm}]: 138.1,127.7,126.0,120.7,118.3,118.2,110.0,58.1$, 34.3, 31.9, 29.7, 29.6, 29.5, 29.4, 29.2, 25.3, 22.6, 14.1. Calcd for $\mathrm{C}_{35} \mathrm{H}_{49} \mathrm{Br}_{2} \mathrm{~N}$ (643.59): C, 65.32; $\mathrm{H}$, 
2,6-Dibromo-4-(p-(1-decylundecyloxy)phenyl)-4H-benzo[def]carbazole (5b). Dibromobenzo-carbazole 5b was similarly synthesized according to the procedure for 5a, giving yellow oil (0.48 $\mathbf{g}$, 96\%). ${ }^{1} \mathrm{H}$ NMR $\left(400 \mathrm{MHz}, \mathrm{CDCl}_{3}\right) \delta[\mathrm{ppm}]: 7.99(\mathrm{~s}, 2 \mathrm{H}), 7.96(\mathrm{~s}, 2 \mathrm{H}), 7.75(\mathrm{~s}, 2 \mathrm{H}), 7.62$ (d, J=9.1 $\mathrm{Hz} 2 \mathrm{H}), 7.14(\mathrm{~d}, \mathrm{~J}=9.1 \mathrm{~Hz} 2 \mathrm{H}), 4.32(\mathrm{~m}, 1 \mathrm{H}), 1.73-1.69$ (m, 4H), 1.33-1.27 (m, 32H), 0.90-0.85 (m, $6 \mathrm{H}) .{ }^{13} \mathrm{C}$ NMR $\left(100 \mathrm{MHz}, \mathrm{CDCl}_{3}\right) \delta[\mathrm{ppm}]: 157.8,140.8,130.3,127.8,126.2,126.0,121.2,120.1$, 119.3, 117.0, 109.9, 78.6, 33.9, 31.9, 31.5, 29.7, 29.6, 29.3, 25.4, 22.7, 22.6, 14.1. Calcd for $\mathrm{C}_{41} \mathrm{H}_{53} \mathrm{Br}_{2} \mathrm{NO}$ (735.69): C, 66.84; H, 7.26; N, 1.90. Found: C, 66.47; H, 7.50; N, 1.75.

4-(1-Decylundecyl)-4H-benzo[def]carbazole (6a). Dibromobenzocarbazole 5a (0.8 g, 1.24 mmol) was dissolved in $12.5 \mathrm{~mL}$ of anhydrous THF and cooled to $-78{ }^{\circ} \mathrm{C}$ under nitrogen atmosphere, in which 1.6 M n-BuLi/hexane solution $(1.63 \mathrm{~mL}, 2.6 \mathrm{mmol})$ was added dropwise with stirring. The mixture was kept at $-78{ }^{\circ} \mathrm{C}$ for $20 \mathrm{~min}$ and then $0.4 \mathrm{~mL}$ of methanol was added. The reaction mixture was stirred at room temperature for $1 \mathrm{~h}$, quenched with $40 \mathrm{~mL}$ of water, and extracted with dichloromethane. After drying over $\mathrm{MgSO}_{4}$ and the solvent evaporation, the crude product was purified by column chromatography (silica gel, hexane as an eluent) to give a white solid $(0.428 \mathrm{~g}$, 72\%). ${ }^{1} \mathrm{H}$ NMR (400 MHz, $\left.\mathrm{CDCl}_{3}\right) \delta[\mathrm{ppm}]: 8.05$ (s, 2H), 7.81(t, J=7.8 Hz 2H), 7.73 (d, J= 7.3 Hz $2 \mathrm{H}), 7.54(\mathrm{~d}, \mathrm{~J}=7.8 \mathrm{~Hz} 2 \mathrm{H}), 4.66(\mathrm{~m}, 1 \mathrm{H}), 2.38-2.35(\mathrm{~m}, 2 \mathrm{H}), 2.02-1.99(\mathrm{~m}, 2 \mathrm{H}), 1.24-1.09$ (m, $32 \mathrm{H}), 0.90-0.82(\mathrm{~m}, 6 \mathrm{H}) .{ }^{13} \mathrm{C} \mathrm{NMR}\left(100 \mathrm{MHz}, \mathrm{CDCl}_{3}\right) \delta[\mathrm{ppm}]: 129.4,127.4,126.5,126.0,121.6$, $115.9,114.5,57.6,34.5,31.9,31.8,29.7,29.6,29.4,29.3,25.4,22.6,14.1$.

1,7-Dibromo-4-(1-decylundecyl)-4H-benzo[def]carbazole (7a). A mixture of $6 \mathbf{a}(0.35 \mathrm{~g}, 0.72 \mathrm{mmol})$ and $\mathrm{NBS}(0,26 \mathrm{~g}, 1.44 \mathrm{mmol})$ in $\mathrm{CHCl}_{3}(3.5 \mathrm{~mL})$ was stirred at $40{ }^{\circ} \mathrm{C}$ for $8 \mathrm{~h}$ under a nitrogen atmosphere. After cooling to room temperature, the mixture was poured into water. After extraction with dichloromethane, drying over $\mathrm{MgSO}_{4}$ and evaporation of the solvent, the crude product was purified by column chromatography (silica gel, hexane as an eluent) to give a white solid $(0.327 \mathrm{~g}$, 70\%). ${ }^{1} \mathrm{H}$ NMR (400 MHz, $\left.\mathrm{CDCl}_{3}\right) \delta$ [ppm]: 8.17 (s, 2H), 7.97 (d, J= 7.7 Hz 2H), $7.43(\mathrm{~d}, \mathrm{~J}=7.8 \mathrm{~Hz}$ $2 \mathrm{H}), 4.59(\mathrm{~m}, 1 \mathrm{H}), 2.33-2.17(\mathrm{~m}, 2 \mathrm{H}), 1.98-1.95(\mathrm{~m}, 2 \mathrm{H}), 1.25-1.08(\mathrm{~m}, 32 \mathrm{H}), 0.88-0.82(\mathrm{~m}, 6 \mathrm{H})$. ${ }^{13} \mathrm{C}$ NMR $\left(100 \mathrm{MHz}, \mathrm{CDCl}_{3}\right) \delta[\mathrm{ppm}]: 140.1,133.8,129.9,127.6,126.1,108.4,57.9,34.4,31.8$, 31.6, 29.6, 29.4, 29.3, 29,2, 26.0, 22.6, 14.1.

Poly[8,9-dihydro-N-(1-decylundecyl)-4H-benzo[def]carbazole-2,6-ylene] (PECza). Under an argon atmosphere, a solution of bis(1,5-cyclooctadiene)nickel $(0)\left(\mathrm{Ni}(\operatorname{cod})_{2}\right)(0.28 \mathrm{~g}, 1.03 \mathrm{mmol})$, 2,2'-bipyridine (bpy) $(0.18 \mathrm{~g}, 1.15 \mathrm{mmol})$ and 1,5-cyclooctadiene (cod) $(0.25 \mathrm{~g}, 2.38 \mathrm{mmol})$ in DMF $(2.5 \mathrm{~mL})$ was heated to $80{ }^{\circ} \mathrm{C}$ for $30 \mathrm{~min}$. The $4 \mathbf{a}(0.301 \mathrm{~g}, 0.46 \mathrm{mmol})$ dissolved in THF $(2.5 \mathrm{~mL})$ under argon was added to the DMF solution. The reaction solution was heated at $80{ }^{\circ} \mathrm{C}$ for 3 days. After the reaction solution was cooled to room temperature, the resultant polymer was precipitated from methanol/ $\mathrm{HCl}$ aq, and reprecipitated from methanol/ $\mathrm{NH}_{3}$ aq and from methanol, respectively. The precipitate was successively extracted with acetone, hexane and $\mathrm{CHCl}_{3}$ by Soxhlet extraction. The $\mathrm{CHCl}_{3}$ extract was again precipitated from methanol. PECza was obtained as a yellow soild (0.21 g, 92\%). ${ }^{1} \mathrm{H}$ NMR (400 MHz, $\left.\mathrm{CDCl}_{3}\right) \delta[\mathrm{ppm}]: 7.48(\mathrm{~s}, 2 \mathrm{H}), 7.32(\mathrm{~s}, 2 \mathrm{H}), 4.56-4.54(\mathrm{~m}, 1 \mathrm{H})$, $3.50(\mathrm{~s}, 4 \mathrm{H}), 2.36(\mathrm{~m}, 2 \mathrm{H}), 1.99-1.96(\mathrm{~m}, 2 \mathrm{H}), 1.32-1.23(\mathrm{~m}, 32 \mathrm{H}), 0.90-0.82(\mathrm{~m}, 6 \mathrm{H})$. Calcd for $\mathrm{C}_{35} \mathrm{H}_{53} \mathrm{~N}$ (487.82): C, 86.18; H, 10.95; N, 2.87. Found: C, 86.25; H, 10.24; N, 2.95. 
Poly[8,9-dihydro-N-(p-(1-decylundecyloxy)phenyl)-4H-benzo[def]carbazole-2,6-ylene] (PECzb). In a similar way to the synthetic procedure for PECza, polymerization of $\mathbf{4 b}$ gave PECzb as a yellow solid (0.22 g, 94\%). ${ }^{1} \mathrm{H}$ NMR $\left(400 \mathrm{MHz} \mathrm{CDCl}_{3}\right) \delta[\mathrm{ppm}]: 7.63(\mathrm{~d}, \mathrm{~J}=8.4 \mathrm{~Hz} 2 \mathrm{H}), 7.51(\mathrm{~s}$, 2H), 7.32 (s, 2H), 7.08 (d, J= 8.4 Hz 2H), 4.27 (m, 1H), 3.47 (s, 4H), 1.70-1.66 (m, 4H), 1.30-1.24 (m, 32H), 0.90-0.83 (m, 6H). Calcd for $\mathrm{C}_{41} \mathrm{H}_{57} \mathrm{NO}$ (645.61): C, 84.92; H, 9.91; N 2.42. Found: C, 84.95; H, 9.32; N, 2.56.

Poly[4-(1-decylundecyl)-4H-benzo[def]carbazole-2,6-ylene] (PBCza). Similarly, polymerization of 5a gave PBCza as a yellow solid $(0.16 \mathrm{~g}, 91 \%) .{ }^{1} \mathrm{H}$ NMR $\left(400 \mathrm{MHz}, \mathrm{CDCl}_{3}\right) \delta[\mathrm{ppm}]: 8.25$ (s, 2H), $8.20(\mathrm{~s}, 2 \mathrm{H}), 8.03(\mathrm{~s}, 2 \mathrm{H}), 4.90(\mathrm{~m}, 1 \mathrm{H}), 2.60(\mathrm{~m}, 2 \mathrm{H}), 2.18(\mathrm{~m}, 2 \mathrm{H}), 1.41-1.17$ (m, 32H), 0.90-0.78 (m, 6H). Calcd for $\mathrm{C}_{35} \mathrm{H}_{51} \mathrm{~N}$ (485.80): C, 86.53; H, 10.28; N, 2.88. Found: C, 86.35; H, 10.28; N, 2.81 .

Poly[4-(p-(1-decylundecyloxy)phenyl)-4H-benzo[def]carbazole-2,6-ylene] (PBCzb). Similarly, polymerization of $\mathbf{5 b}$ gave $\mathbf{P B C z b}$ as a yellow solid $(1.1 \mathrm{~g}, 65 \%) .{ }^{1} \mathrm{H} \mathrm{NMR}\left(400 \mathrm{MHz}, \mathrm{CDCl}_{3}\right) \delta$ [ppm]: $8.21(\mathrm{~s}, 4 \mathrm{H}), 8.08(\mathrm{~s}, 2 \mathrm{H}), 7.87(\mathrm{~d}, \mathrm{~J}=7.6 \mathrm{~Hz} 2 \mathrm{H}), 7.18(\mathrm{~d}, \mathrm{~J}=8 \mathrm{~Hz} 2 \mathrm{H}), 4.32(\mathrm{~m}, 1 \mathrm{H})$, 1.84-1.73 (m, 4H), 1.25-1.23 (m, 32H), 0.88-0.82 (m, 6H). Calcd for $\mathrm{C}_{41} \mathrm{H}_{55} \mathrm{NO}$ (577.90): C, 85.21; H, 9.59; N, 2.42. Found: C, 84.62; H, 9.41; N, 2.29.

Poly[4-(1-decylundecyl)-4H-benzo[def]carbazole-1,7-ylene] (1,7-PBCza). Similarly polymerization of 7a gave 1,7-PBCza as a green solid $(0.15 \mathrm{~g}, 72 \%) .{ }^{1} \mathrm{H} \mathrm{NMR}\left(400 \mathrm{MHz}, \mathrm{CDCl}_{3}\right) \delta$ [ppm]: $8.07(\mathrm{~s}, 4 \mathrm{H}), 7.68(\mathrm{~s}, 2 \mathrm{H}), 4.76(\mathrm{~m}, 1 \mathrm{H}), 2.47(\mathrm{~m}, 2 \mathrm{H}), 2.10(\mathrm{~m}, 2 \mathrm{H}), 1.30-1.16(\mathrm{~m}, 32 \mathrm{H})$, 0.80-0.77 (m, 6H). Calcd for $\mathrm{C}_{35} \mathrm{H}_{51} \mathrm{~N}$ (485.80): C, 86.53; H, 10.28; N, 2.88. Found: C, 85.95; H, $10.35 ; \mathrm{N}, 2.92$.

\subsection{General method and instrumentation}

All synthetic manipulations were performed by a standard technique using a Schlenk tube under an argon atmosphere. Column chromatography was performed using a silica gel (Kanto Chem., 60 $\mathrm{N}, 63-120 \mathrm{~mm}$ ). Nuclear magnetic resonance (NMR) spectra were recorded on a JEOL JNM-ECS 400 spectrometer. The ${ }^{1} \mathrm{H}$ and ${ }^{13} \mathrm{C}$ chemical shifts are given in units of $\delta$ (ppm) relative to $\delta$ (TMS) $=0.00$ and $\delta\left(\mathrm{CDCl}_{3}\right)=77.0 \mathrm{ppm}$, respectively. Photoabsorption in the range of ultraviolet-visible (UV-vis) and photoluminescence (PL) measurements of the polymer samples in $\mathrm{CHCl}_{3}$ and in a form of a thin film coating on a quartz glass were performed using a Shimadzu UV-1800 spectrophotometer and an F-4500 fluorescence spectrophotometer (Hitachi) at room temperature. The fluorescence quantum yield $\left(\phi_{\mathrm{fl}}\right)$ in $\mathrm{CHCl}_{3}$ were relative to 9,10-diphenylanthracene in cyclohexane $\left(\phi_{\mathrm{fl}}=0.90\right)$ as a standard. The number-average molecular weight $\left(M_{\mathrm{n}}\right)$ and the weight-average molecular weight $\left(M_{\mathrm{w}}\right)$ of the polymers were estimated by a gel permeation chromatography (GPC) system (Shimadzu, LC solution) using polystyrene standards with $\mathrm{CHCl}_{3}$ as an eluent. Cyclic voltammetry (CV) of polymers in thin film on a Pt disk was performed at a scan rate of $50 \mathrm{mV} / \mathrm{s}$ in acetonitrile containing $0.1 \mathrm{M} \mathrm{Et}_{4} \mathrm{NBF}_{4}$ at room temperature under Ar using a saturated calomel electrode (SCE) as the reference and platinum wire as the counter electrode. The electrochemical data (vs SCE) obtained by cyclic voltammetry was made a correction with the redox potential $(4.8 \mathrm{eV}$ ) of ferrocene/ferricinium [20,21]. Elemental analyses were carried out with 
a Perkin-Elmer type 2400 apparatus. Thermal gravimetric analysis (TGA) and differential thermal analysis (DTA) were carried out by an Extar 7000 TG/DTA (Seiko) analyzer at a heating rate of $10{ }^{\circ} \mathrm{C} \mathrm{min}^{-1}$ in an argon atmosphere.

\section{Results and discussion}

\subsection{Synthesis}

The general synthetic routes toward the monomers and polymers are outlined in Scheme 2 and Scheme 3. The introduction of the 1-decylundecyl group at $\mathrm{N}$-position of $\mathbf{3}$ was carried out by the procedure reported previously [22], giving 4a. The $p$-(1-decylundecyloxy)phenyl group was introduced into $\mathrm{N}$-position of $\mathbf{3}$ according to the procedure in our previous report [23], giving $\mathbf{4 b}$. Monomers $5 \mathbf{a}$ and $\mathbf{5 b}$ were prepared by oxidation of $\mathbf{4 a}$ and $\mathbf{4 b}$ with DDQ, respectively. In order to obtain 7a, debromination of $\mathbf{5 a}$ and successive bromination of $\mathbf{6 a}$ were performed. Homopolymerizations of $\mathbf{4 a}, \mathbf{4 b}, \mathbf{5 a}, \mathbf{5 b}$ and $\mathbf{7 a}$ by Yamamoto reaction [24] afforded PECza, PECzb, PBCza, PBCzb and 1,7-PBCza, respectively.

All of the polymers were soluble in usual organic solvents such as toluene, THF, $\mathrm{CHCl}_{3}$, and so forth. GPC results were summarized in Table 1 . They have good processability to make thin cast films. The polymers showed $M_{\mathrm{n}}$ larger than $10 \mathrm{~kg} \mathrm{~mol}^{-1}$, the polydispersities $\left(M_{\mathrm{w}} / M_{\mathrm{n}}\right)$ about 1.5 , and the degree of polymerization (DP) higher than 27. TGA results are shown in Fig. 2. All the polymers showed a good thermal stability, and their temperatures of $5 \mathrm{wt} \%$ loss in TGA $\left(T_{\mathrm{d}}\right)$ were around $400{ }^{\circ} \mathrm{C}$, respectively. The polymers with $\mathrm{N}$-phenyl side group showed lower $T_{\mathrm{d}}$ values. This result suggests that thermal stability of PECZb and PBCZb are lower than those of $\mathrm{N}$-alkyl substituted polymers (PECZa, PBCZa, and 1,7-PBCZa), which might be due to suppression of intimate interaction between polymer chains by steric effect of the rigid N-phenyl group.

\section{Table 1}

GPC and TGA results of the polymers.

\begin{tabular}{cccccc}
\hline Polymer & $\begin{array}{c}M_{\mathrm{n}} \\
\left(\mathrm{kg} \mathrm{mol}^{-1}\right)\end{array}$ & $\begin{array}{c}M_{\mathrm{w}} \\
\left(\mathrm{kg} \mathrm{mol}^{-1}\right)\end{array}$ & $M_{\mathrm{w}} / M_{\mathrm{n}}$ & $\mathrm{DP}^{\mathrm{a}}$ & $T_{\mathrm{d}}\left({ }^{\circ} \mathrm{C}\right)^{\mathrm{b}}$ \\
PECza & 78.3 & 107.7 & 1.38 & 161.4 & 464 \\
PECzb & 121.1 & 229.7 & 1.89 & 209.8 & 377 \\
PBCza & 13.3 & 18.9 & 1.42 & 27.6 & 422 \\
PBCzb & 299.2 & 528.2 & 1.76 & 520.3 & 366 \\
1,7-PBCza & 13.0 & 19.9 & 1.57 & 27.0 & 436 \\
\hline
\end{tabular}

${ }^{\mathrm{a}} \mathrm{DP}$ was estimated from $M_{\mathrm{n}}$.

${ }^{\mathrm{b}}$ Temperature of $5 \%$ weight loss determined by TGA under an argon atmosphere. 


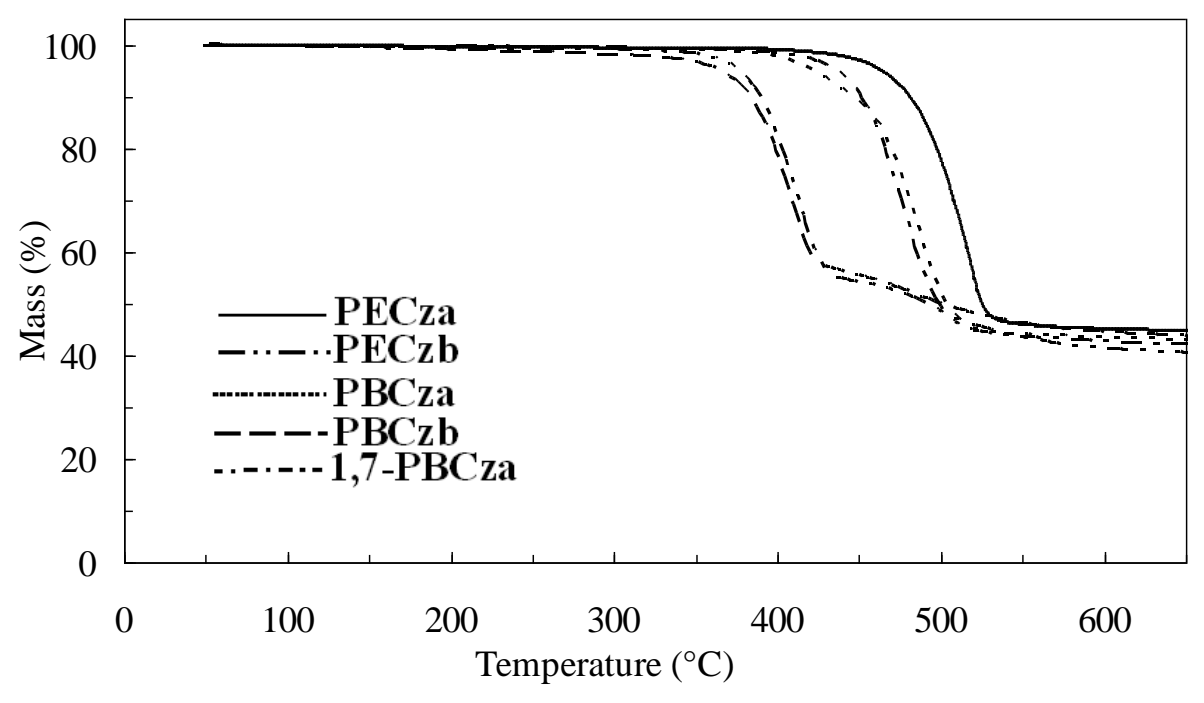

Fig. 2 TGA curves of the polymers.

\subsection{Optical properties.}

The photophysical properties of dilute solution and thin films of all the polymers were investigated by UV-vis and PL, and the results are shown in Fig. 3 and Fig. 4. The UV-vis and PL spectra data for the polymer are summarized in Table 2 .
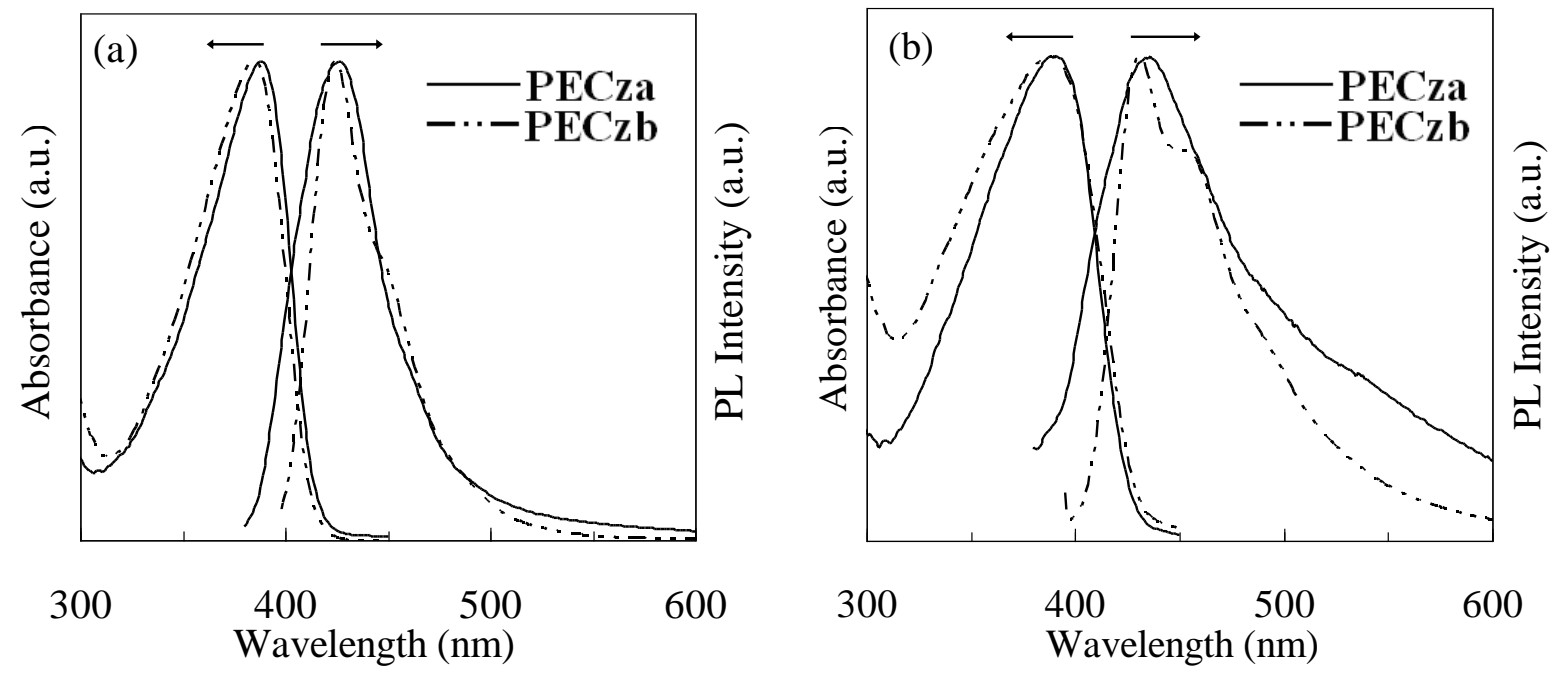

Fig. 3 UV-vis and PL spectra of PECza and PECzb in $\mathrm{CHCl}_{3}$ (a) and flim state (b).

Fig. 3a shows the absorption and PL spectra of PECza and PECzb in $\mathrm{CHCl}_{3}$. The absorption feature with a pronounced $\pi-\pi^{*}$ transition peak around $385 \mathrm{~nm}$ observed for PECza was almost the same as that of PECzb. The absorption maxima ( $\lambda_{\max }$ Abs $)$ of the series of PECz were similar with those of poly $(2,7$-carbazole $)$ s $(\mathbf{P C z})\left(\lambda_{\max }\right.$ Abs $\left.=387 \mathrm{~nm}\right)[25,26]$. The PL emission peak maxima ( $\lambda_{\max , \text { Em}}$ ) of the polymers in $\mathrm{CHCl}_{3}$ were observed at $426 \mathrm{~nm}$ for PECza and $424 \mathrm{~nm}$ for PECzb. The fluorescence quantum yields ( $\left.\phi_{\mathrm{fl}}\right)$ of PECza and PECzb in $\mathrm{CHCl}_{3}\left(\phi_{\mathrm{fl}}=0.45,0.67\right)$ were lower than those of PCz $\left(\phi_{\mathrm{fl}} \approx 1\right)$. The Stokes shifts $\left(\Delta \lambda=\left(\lambda_{\max }, \mathrm{Em}\right)-\left(\lambda_{\max }\right.\right.$, Abs $\left.)\right)$ of PECza and PECzb in 
$\mathrm{CHCl}_{3}$ were 38 and $39 \mathrm{~nm}$, respectively, which were slightly larger than those of $\mathbf{P C z}$ (ca. $35 \mathrm{~nm}$ ) [26]. The larger $\Delta \lambda$ is responsible for the lager structural change between ground and excited states, which might affect lowering $\phi_{\mathrm{fl}}$.

The absorption and PL spectra of PECza and PECzb in the thin film state are shown in Fig. $3 b$. Their absorption spectra were almost the same each other, and the energy gaps $\left(E_{\mathrm{g}}\right)$ between highest occupied molecular orbital (HOMO) and lowest unoccupied molecular orbital (LUMO) of the PECza and PECzb estimated from the onset of the absorption spectra in the film state were 2.94 and $2.96 \mathrm{eV}$, respectively, which were almost the same with those of $\mathbf{P C z}(2.92 \mathrm{eV})$.
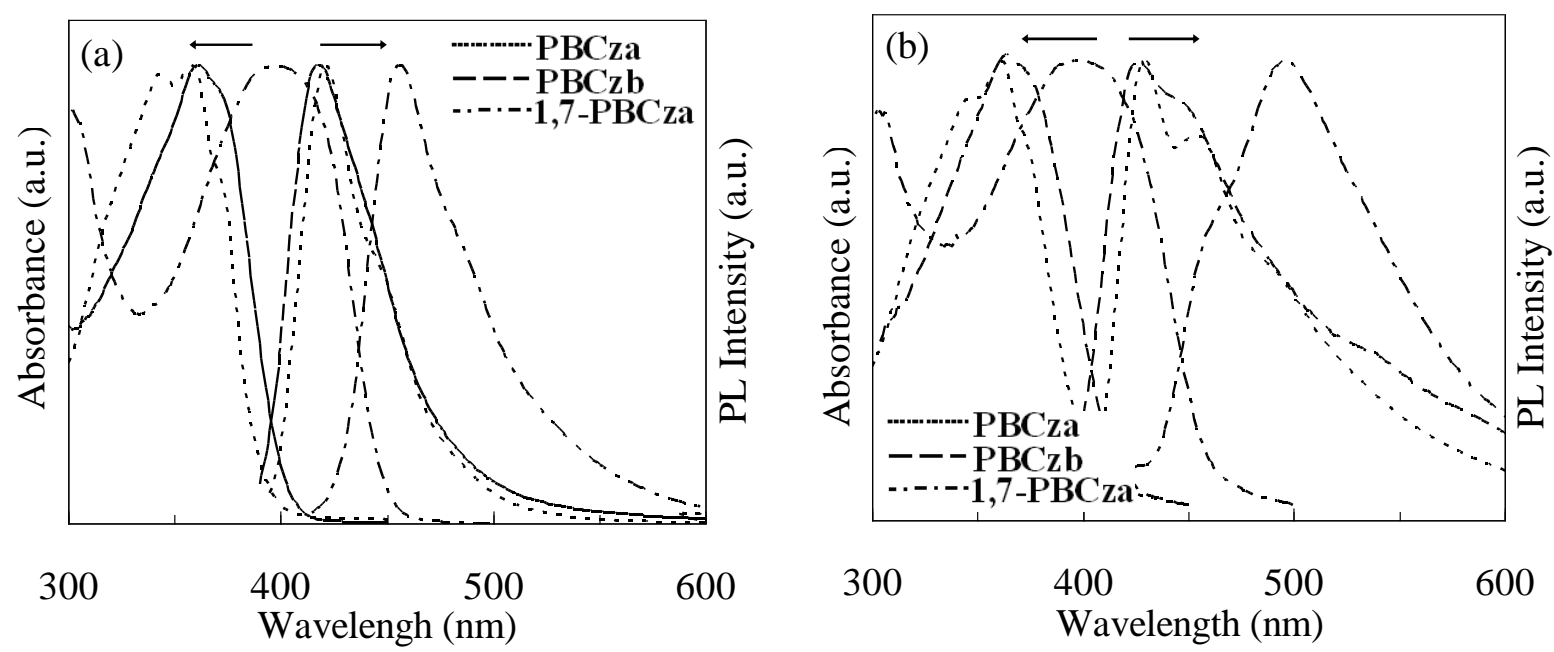

Fig. 4 UV-vis and PL spectra of PBCza, PBCzb and 1,7-PBCza in $\mathrm{CHCl}_{3}$ (a) and film state (b).

Next, absorption and PL spectra of $\mathbf{P B C z}$ in $\mathrm{CHCl}_{3}$ are depicted in Fig. 4a. The observed $\lambda_{\max }$, Abs at $358 \mathrm{~nm}$ for PBCza and $361 \mathrm{~nm}$ for PBCzb owing to $\pi-\pi^{*}$ transition of conjugated polymer main chains were unexpectedly blue-shifted in comparison to $\mathbf{P C z}$ and poly(2,7-phenanthrene)s [27, 28 , although they include an extended $\pi$-conjugated structure of phenanthrene in the unit. Consequently, they fluoresced in deep-blue color in $\mathrm{CHCl}_{3}$, and the $\lambda_{\max }$, Em of PBCza and PBCzb were observed at $421 \mathrm{~nm}$ and $419 \mathrm{~nm}$, respectively. The $\Delta \lambda$ observed for PBCza and PBCzb in $\mathrm{CHCl}_{3}$ were 63 and $58 \mathrm{~nm}$, which were larger than thoseof PECz and $\mathbf{P C z}$ (35-39 nm). The larger $\Delta \lambda$ of PBCza and PBCzb might be responsible for the lower $\phi_{11}$ than those of of PECz and PCz. These results suggest that the 4,5-ethenylene bridge and the N-bridge cooperatively control each ring strain and 2,7-conjugation of polycarbazole and polyphenanthrene i.e., an optimized structure of $\mathbf{B C z}$ calculated by DFT showed both features of an elongated C-N linked $\mathbf{C z}$ and a strained phenanthrene with the imino bridge (Fig. 1S, Table 1S and Table 2S, Supporting information).

Fig. 4b shows the absorption and PL spectra of PBCza and PBCzb in the thin film state. Due to some aggregations or interactions between the polymer chains in the thin film state, the $\lambda_{\max }$, Abs of PBCza and PBCzb were slightly red-shifted than those in $\mathrm{CHCl}_{3}$. The $E_{\mathrm{g}}$ of $\mathbf{P B C z a}(3.15 \mathrm{eV})$ and PBCzb (3.05 eV) were larger than those of PECz and PCz. The large $E_{\mathrm{g}}$ values of $\mathrm{PBCz}$ were responsible for the blue shifts of $\lambda_{\max }$, Abs in solution. The PL spectra of $\mathbf{P B C z}$ in the film state showed tailing bands that might involve vibronic feature and excimeric emissions in the longer wavelength region.

The absorption and PL spectra of 1,7-PBCza in $\mathrm{CHCl}_{3}$ are also shown in Fig. 4a. The $\lambda_{\max }$ Abs 
was observed at $396 \mathrm{~nm}$, which was considerably red-shifted in comparison with those of poly $(3,6$-carbazole $) s\left(\lambda_{\max }\right.$, Abs $=$ ca. $\left.310 \mathrm{~nm}\right)[29,30]$. The large red-shift is due to effect of the added 4,5-ethenylene bridge at the $\mathbf{C z}$ ringwith extension of $\pi$-conjugation along the main chain through the 1,7-linkage and the bridge. The $\lambda_{\max }$, Em was observed at $456 \mathrm{~nm}$, and the $\Delta \lambda$ was $60 \mathrm{~nm}$. Interestingly, the $\phi_{\mathrm{fl}}(=0.45)$ was surprisingly high compared with those ( $\phi_{\mathrm{fl}}=0.04$ to 0.06$)$ for poly(3,6-carbazole)s in dichloromethane [30]. The enhancement of quantum yields might be due to stabilization of energy states of 1,7-PBCza by the extended $\pi$-conjugation. Fig. $4 \mathrm{~b}$ shows the absorption and PL spectra of 1,7-PBCza in the thin film state. The $\lambda_{\max }$, Abs of 1,7-PBCza was largely red-shifted compared with those of PECz, PBCz, and PCz. The $E_{\mathrm{g}}$ of 1,7-PBCza is exceptionally narrow compared with those of poly(3,6-carbazole)s $(3.2 \mathrm{eV})$ [30]. The emission band of 1,7-PBCza was much broader and shifted to lower energy compared with that ( $\lambda_{\max }$, $\mathrm{Em}=426 \mathrm{~nm})$ of poly(3,6-carbazole)s [30]. These photophysical results suggest that 1,7-PBCza is a potential polymer having light-emitting as well as hole transporting functions to be applied in PLEDs.

\section{Table 2}

Optical properties, HOMO-LUMO energy gaps, and the energy levels of the polymers.

\begin{tabular}{|c|c|c|c|c|c|c|c|c|c|}
\hline \multirow{2}{*}{ Polymer } & \multicolumn{2}{|c|}{$\lambda_{\max , \mathrm{Abs}}(\mathrm{nm})$} & \multicolumn{2}{|c|}{$\lambda_{\max , \mathrm{Em}}(\mathrm{nm})$} & \multirow{2}{*}{$\Delta \lambda^{\mathrm{a}}(\mathrm{nm})$} & \multirow{2}{*}{$\phi_{\mathrm{fl}}$} & \multirow{2}{*}{$E_{\mathrm{g}}(\mathrm{eV})$} & \multirow{2}{*}{$\begin{array}{c}E_{\text {HOMO }} \\
(\mathrm{eV})\end{array}$} & \multirow{2}{*}{$\begin{array}{c}E_{\mathrm{LOMO}} \\
(\mathrm{eV})\end{array}$} \\
\hline & in $\mathrm{CHCl}_{3}$ & film & in $\mathrm{CHCl}_{3}$ & film & & & & & \\
\hline PECza & 388 & 388 & 426 & 436 & 38 & 0.45 & 2.96 & -5.59 & -2.54 \\
\hline PECzb & 385 & 389 & 424 & 431 & 39 & 0.67 & 2.94 & -5.53 & -2.59 \\
\hline PBCza & 358 & 361 & 421 & 429 & 63 & 0.30 & 3.15 & -5.50 & -2.44 \\
\hline PBCzb & 361 & 361 & 419 & 426 & 58 & 0.48 & 3.05 & -5.49 & -2.44 \\
\hline 1,7-PBCza & 396 & 398 & 456 & 495 & 60 & 0.45 & 2.77 & -5.37 & -2.60 \\
\hline
\end{tabular}

${ }^{\text {a }}$ Stokes shifts measured in $\mathrm{CHCl}_{3}$.

\subsection{Electrochemical properties}

Electrochemical data of the polymers were measured by cyclic voltammetry (CV) and their voltammograms are shown in Fig. 5 and related data are summarized in Table 2. The energy levels of HOMO $\left(E_{\mathrm{HOMO}}\right)$ estimated from the onset potential of an oxidation peak of PECza and PECzb were -5.59 and $-5.53 \mathrm{eV}$, respectively, which were similar to those of $\mathbf{P C z}$ (ca. $-5.6 \mathrm{eV}$ ) [26]. The

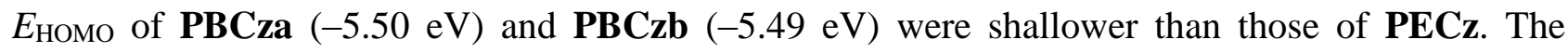
shallowest $E_{\text {Hомо }}(-5.37 \mathrm{eV})$ was observed for 1,7-PBCza, although it was deeper than those of the comparison poly(3,6-carbazole)s (ca. $-5.10 \mathrm{eV})$ [30].

Since it was difficult to recognize onset potentials of reduction waves of the homopolymers in the film state, the energy levels of the LUMO ( $\left.E_{\text {LUMO }}\right)$ were estimated from the $E_{\text {HOMO }}$ and optical band gap $\left(E_{\mathrm{g}}\right)$ using the equation, $E_{\mathrm{Lumo}}=E_{\mathrm{HOMO}}+E_{\mathrm{g}}$. The $E_{\mathrm{LUMO}}$ of PECza, PECzb, PBCza, PBCzb and 1,7-PBCza were determined to be $-2.54,-2.59,-2.44,-2.44$ and $-2.60 \mathrm{eV}$, respectively. 


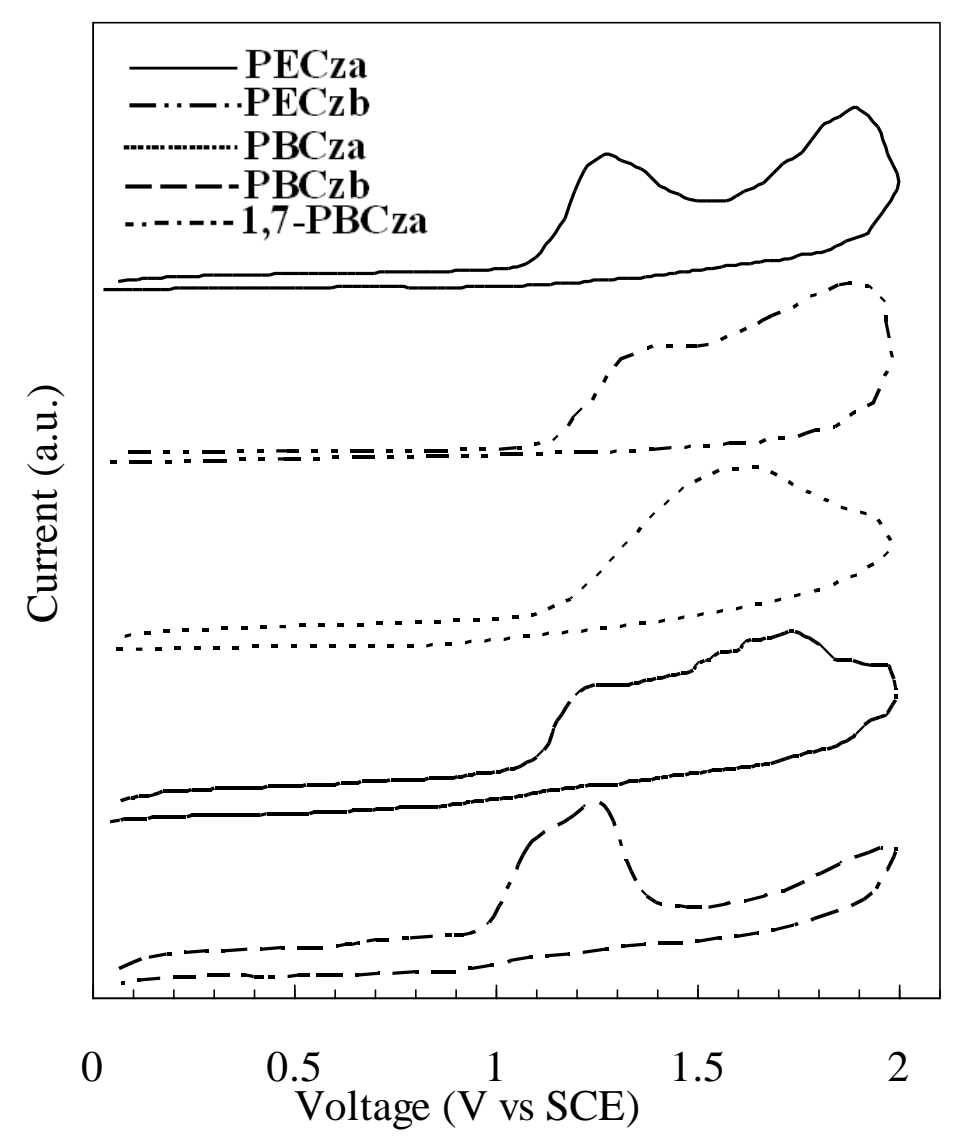

Fig. 5. Cyclic voltammograms of PECza, PECzb, PBCza, PBCzb and 1,7-PBCza.

To understand the difference of $E_{\mathrm{HOMO}}$ between $\mathbf{P C z}$ and $\mathbf{P B C z}$, the electronic structures of $\mathbf{C z}$ and $\mathbf{B C z}$ were investigated using density functional theory (DFT) in the Gaussian 09 program at the B3LYP/6-31G(d) basis set. Fig. 6 shows the optimized geometry and electron density distributions in the HOMO and LUMO for the different building blocks. It appears that the electron delocalized along the whole rings well on both the HOMO and LUMO of $\mathbf{C z}$ and $\mathbf{B C z}$, therefore scope of delocalization in the $\mathbf{B C z}$ is wider for the larger fused aromatic ring system. As a result, $E_{\mathrm{HOMO}}$ of $\mathbf{B C z}$ is elevated and $E_{\mathrm{g}}$ narrowed compared to those of $\mathbf{C z}$ by the calculation. This calculation also indicates that the $\mathbf{B C z}$ unit can function as phenanthrene by presence of the 4,5-ethenylene bridge of $\mathbf{C z}$.

Considering the electron density maps of HOMO of the $\mathbf{C z}$ and $\mathbf{B C z}$ units, conjugation along the main chain through 2,7-linked $\mathbf{P C z}$ is thought to be more advantageous than 2,6-linked $\mathbf{P B C z}$, because no electron density could be observed in the center of the $\mathbf{B C z}$ unit. Thus, the wider $E_{\mathrm{g}}$ observed for PBCz can be accounted for the characteristic electron distribution of BCz. Similarly, the narrow $E_{\mathrm{g}}$ of 1,7-PBCza can be elucidated by $\pi$-conjugation of 1,7-linkage through 8,9-ethenylene of BCz. 

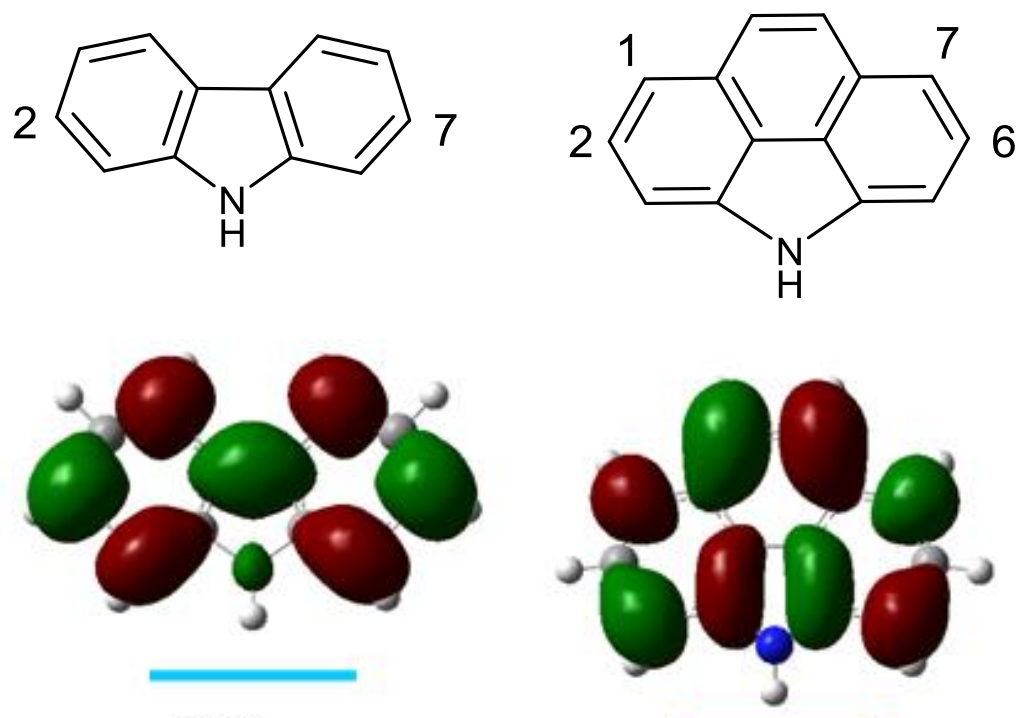

$-0.64 \mathrm{ev}$
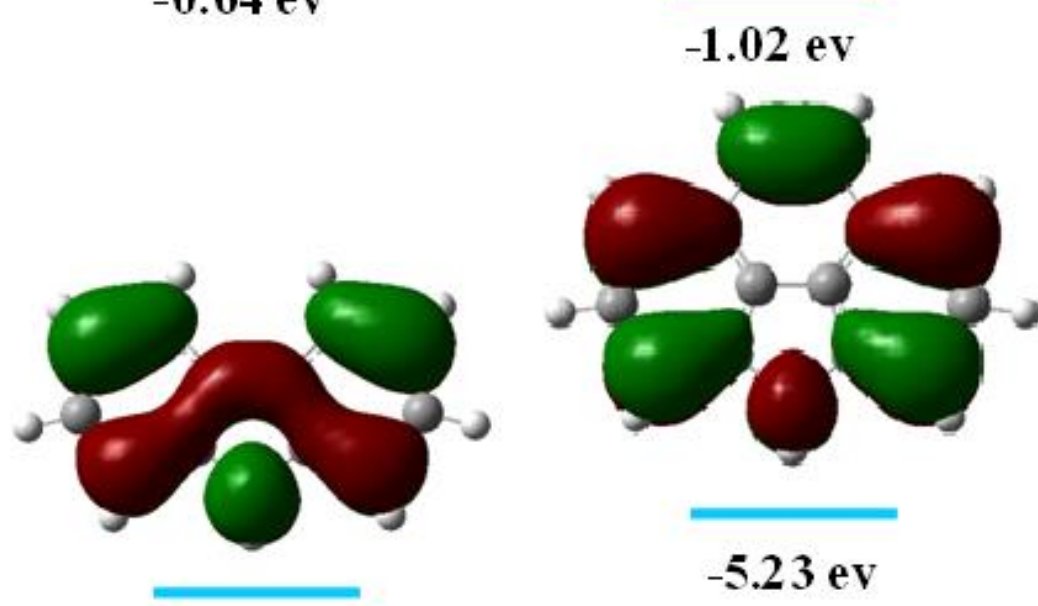

\section{$-5.44 \mathrm{ev}$}

\section{Carbazole}

\section{Benzocarbazole}

Fig. 6 HOMO and LUMO energy levels of carbazole $(\mathbf{C z})$ and benzocarbazole $(\mathbf{B C z})$, optimized by DFT calculation with Gaussian 09 program at the B3LYP/6-31G(d) basis set.

\subsection{X-ray diffraction analysis}

The X-ray diffraction (XRD) analyses were performed to investigate $\pi$-stacking distance and structural order of the polymers in film state, and the results are shown in Fig. 7. PECza and PECzb had a broad diffraction hump observed at about $18-19^{\circ}(\mathrm{d}=4.8,4.7 \AA)$. On the other hand, PBCza, PBCzb and 1,7-PBCza exhibited diffraction humps in the wider angle at $2 \theta=20.50,21.32$, $21.10^{\circ}$, which correspond to $\pi$-stacking distances of $4.33,4.16,4,21 \AA$, respectively. Since all the polymers had no sharp diffraction peaks but only broad humps, these polymers are considered to be amorphous with loose $\pi$-stacking. The smaller $\pi$-stacking distances observed for PBCz suggests that the intermolecular interaction is stronger compared with PECz, which is basically affected by the size of the conjugated planar unit of the polymers. 


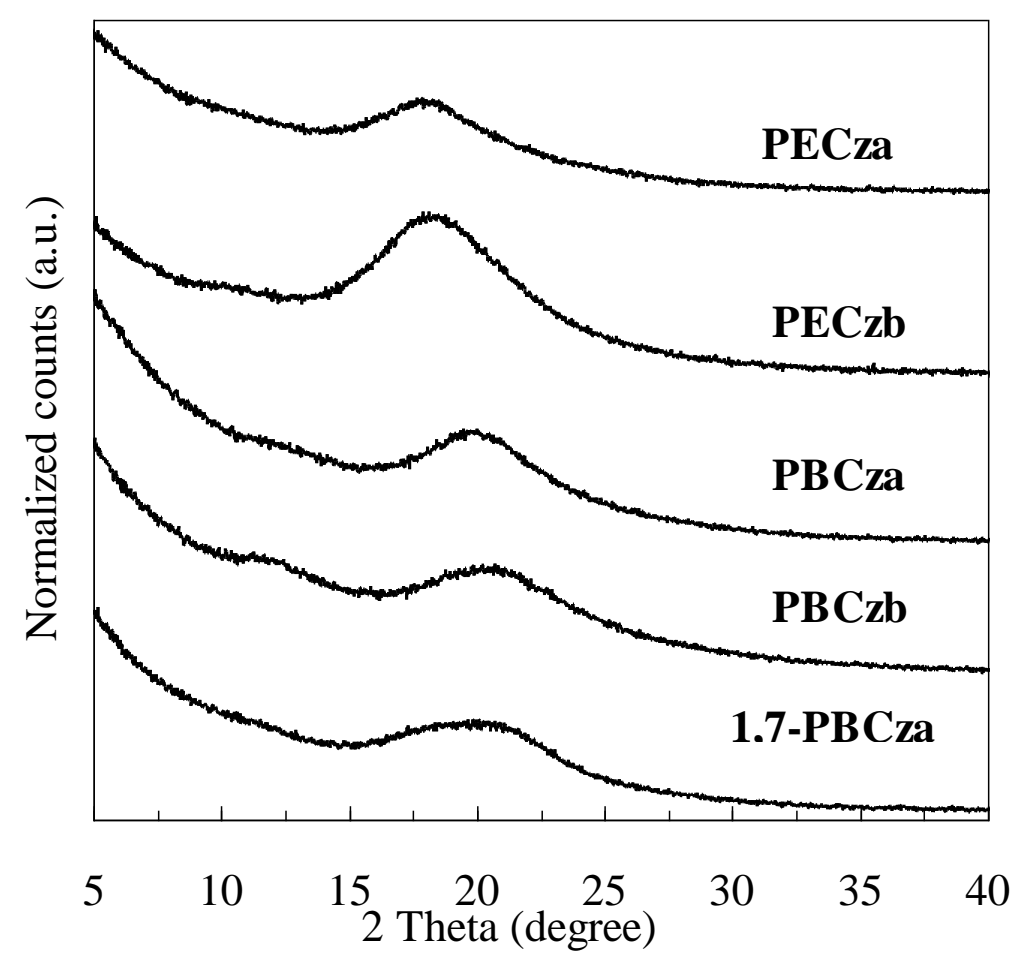

Fig. 7 X-ray diffraction patterns of the homopolymers.

\section{Conclusions}

In this article, we have presented the syntheses and characterizations of 4,5-ethylene bridged poly(carbazole)s (PECza, PECzb) and poly(4H-benzo[def]carbazole)s (PBCza, PBCzb and 1,7-PBCza) as a new series of carbazole-based homopolymers. They had enough high molecular weights, good solubility in common organic solvents, good thermal stability for making thin films and amorphous nature in the film state. PECz showed similar electronic properties of absorption and emission to those of $\mathbf{P C z}$, but the $\phi_{\mathrm{fl}}$ were somewhat lower than those of PCz. On the other hand, poly(2,6-benzocarbazole)s (PBCza and PBCzb) showed unexpectedly blue-shifted absorption bands, the shallower $E_{\mathrm{HOMO}}$, and the wider $E_{\mathrm{g}}$ compared with those of PECz and PCz, although they have the larger $\pi$-conjugation in the monomer unit. These results might be ascribed to the dominant characteristics of poly(2,7-phenanthrene) strained by the N-bridge in PBCz.

The PL emission colors can be evaluated by color coordinates in the Commission Internationale de L'Eclairage (CIE) chromaticity diagram. The CIE $(x, y)$ values of PECza, PECzb, PBCza and PBCzb in $\mathrm{CHCl}_{3}$ were almost identical to $(0.15,0.05)$ in the region of deep blue. In film state, the CIE values for PECz $(0.16,0.15)$ were in the region of blue, while PL emission color of PBCz were shifted to geenish blue but kept in the region of blue $(0.19,0.21)$. The shift of the PL color is ascribed to the stronger intermolecular interaction between the larger planar units of $\mathbf{P B C z}$ as suggested in the XRD results, although they have larger $E_{\mathrm{g}}$ than PECz. From the appropriate $E_{\text {HOMO }}$ around $-5.5 \mathrm{eV}$ for hole injection and appropriate $E_{\mathrm{g}}$ for blue emission, it is considered that PECz and PBCz have potential to be applied in PLED as the blue-light emitting material. On the other hand, 1,7-PBCz is found to have unique properties, i.e., the absorption and emission bands were observed in considerable longer region in wavelength with moderate $\phi_{\mathrm{fl}}$, which were quite different from those of poly(3,6-carbazole)s. According to the dominant character of poly(1,8-phenanthrene) trained by the 8,9 -ethenylene bridge in $1,7-\mathbf{P B C z a}$, it showed the shallowest $E_{\text {HOMO }}$ and narrowest 
$E_{\mathrm{g}}$ of all the homopolymers synthesized in this work. Consequently, it fluoresced in blue green (CIE $(0.20,0.33))$ in the film state. Therefore, the $\mathbf{1 , 7 - B C z}$ unit would rather be applied in a donor component of donor-acceptor-type narrow band gap polymers for organic solar cells.

\section{Appendix A. Supplementary data}

Additional Supporting Information about synthetic procedures, characterizations of other materials, optimized geometric structures, bond angles and bond lengths.

\section{Acknowledgements}

We thanks Chemical Analysis Division, Research Facility Center for Science and Technology, University of Tsukuba, for facilities of the NMR, elemental analysis, TGA and PL measurements.

\section{References}

[1] Y. Xia, R. H. Friend, Macromolecules 38 (2005) 6466-6471.

[2] J. Ye, Z. Chen, M. K. Fung, C. Zheng, X. Ou, X. H. Zhang, Y. Yuan, C. S. Lee, Chem. Mater. 25 (2013) 2630-2637.

[3] G. Grem, G. Leditzky, B. Ullrich and G. Leising, Adv. Mater. 4 (1992) 36-37.

[4] L. Ma, Z. Xie, J. Liu, J. Yang, Y. Cheng, L. Wang, and F. Wang, Appl. Phys. Lett. 87 (2005) 163502.

[5] L. Romaner, A. Pogantsch, P. S. de Freitas, U. Scherf, M. Gaal, E. Zojer, and E. J. W. List, Adv. Funct. Mater. 13 (2003) 597-601.

[6] C. Yang, H. Scheiber, E. J. H. List, J. Jacob, and K. Müllen, Macromolecules 39 (2006) 5213-5221.

[7] S. Qiu, L. Liu, B. Wang, F. Shen, W. Zhang, M. Li, and Y. Ma, Macromolecules 38 (2005) 6782-6788.

[8] M. C. Hung, J. L. Liao, S. A. Chen, S. H. Chen, A. C. Su, J. Am. Chem. Soc. 127 (2005) 14576-14577.

[9] U. Mitschke, P. Bäuerle, J. Mater. Chem. 10 (2000) 1471-1507.

[10] D. Neher, Macromol. Rapid Commun. 22 (2001) 1365-1385.

[11] F. B. Dias, J. Morgado, A. L. Maçanita, P. C. Costa, H. D. Burrows, A. P. Monkman, Macromolecules. 39 (2006) 5854-5864.

[12] J. F. Morin, S. Beaupré, M. Leclerc, I. Lévesque, M. D’Iorio, Appl. Phys. Lett. 80 (2002) 341-343.

[13] M. Kijima, R. Koguchi, S. Abe, Chem. Lett. 34 (2005) 900-901.

[14] M. Kijima, IOP Conf. Series: Materials Science and Engineering. 54 (2014) 012017.

[15] P. L. T. Boudreault, S.Beaupré, M. Leclerc, Polym. Chem. 1 (2010) 127-136.

[16] H. Suh, Y. Jin, S. H. Park, D. Kim, J. Kim, C. Kim, J. K. Kim, K. Lee, Macromolecules. 38 (2005) 6285-6289.

[17] J. V. Grazulevicius, P. Strohriegl, J. Pielichowski, K. Pielichowski, Prog. Polym. Sci. 28 (2003) 1297-1353.

[18] D. Neher, Macromol. Rapid Commun. 22 (2001) 1365-1385.

[19] Z. C. He, C. Zhang, X. F. Xu, L. J. Zhang, L. Huang, J. W. Chen, H. B. Wu, Y. Cao, Adv. Mater. 
23 (2011) 3086-3089.

[20] J. Pommerehne, H. Vestweber, W. Guss, R. F. Mahrt, H. Bássler, M. Porsch, J. Daub. Adv. Mater. 7 (1995) 551-554.

[21] A. K. Agrawal, S. A. Jenekhe, Chem. Mater. 8 (1996) 579-589.

[22] N. Blouin, A. Michaud, M. Leclerc, Adv. Mater. 19 (2007) 2295-2300.

[23] R. Koguchi, N. Kobayashi, M. Kijima, Macromolecules. 42 (2009) 5946-5952.

[24] T. Yamamoto, A. Morita, Y. Muyazaki, T. Maruyama, H. Wakayama, Z. H. Zhou, Y. Nakamura, T. Kanbara, S. Sasaki, K. Kubota, Macromolecules. 25 (1992) 1214-1223.

[25] T. Horii, T. Shinnai, K. Tsuchiya, T. Mori, M. Kijima, J Polym Sci Part A: Polym Chem, 50 (2012) 4557-4562.

[26] N. Kobayashi, R. Koguchi, M. Kijima, Macromolecules. 39 (2006) 9102-9111.

[27] R. Grisorio, G. P. Suranna, P. Mastrorilli, C. F. Nobile, Org. Lett. 9 (2007) 3149-3152.

[28] C. Yang, H. Scheiber, E. J. W. List, J. Jacob, K. Müllen, Macromolecules. 39 (2006) 5213-5221.

[29] Z. B. Zhang, M. Fujiki, H. Z. Tang, M. Motonaga, K. Torimitsu, Macromolecules. 35 (2002) 1988-1990.

[30] A. Iraqi, I. Wataru, J. Polym. Sci., Part A: Polym. Chem. 42 (2004) 6041-6051. 


\section{Highlights}

- New poly(carbazole)s having 4,5-ethenylene and ethylene bridges were synthesized.

- The polymers had appropriate $M_{\mathrm{n}}$, solubility, and $\phi_{\mathrm{fl}}$ to be applied in emissive devices.

- Poly(2,6-benzocarbazole)s had appropriate band gap for blue-light emitting.

- Poly(1,7-benzocarbazole) had narrower band gap than the 2,6-linked ones.

\section{Graphical Abstract}

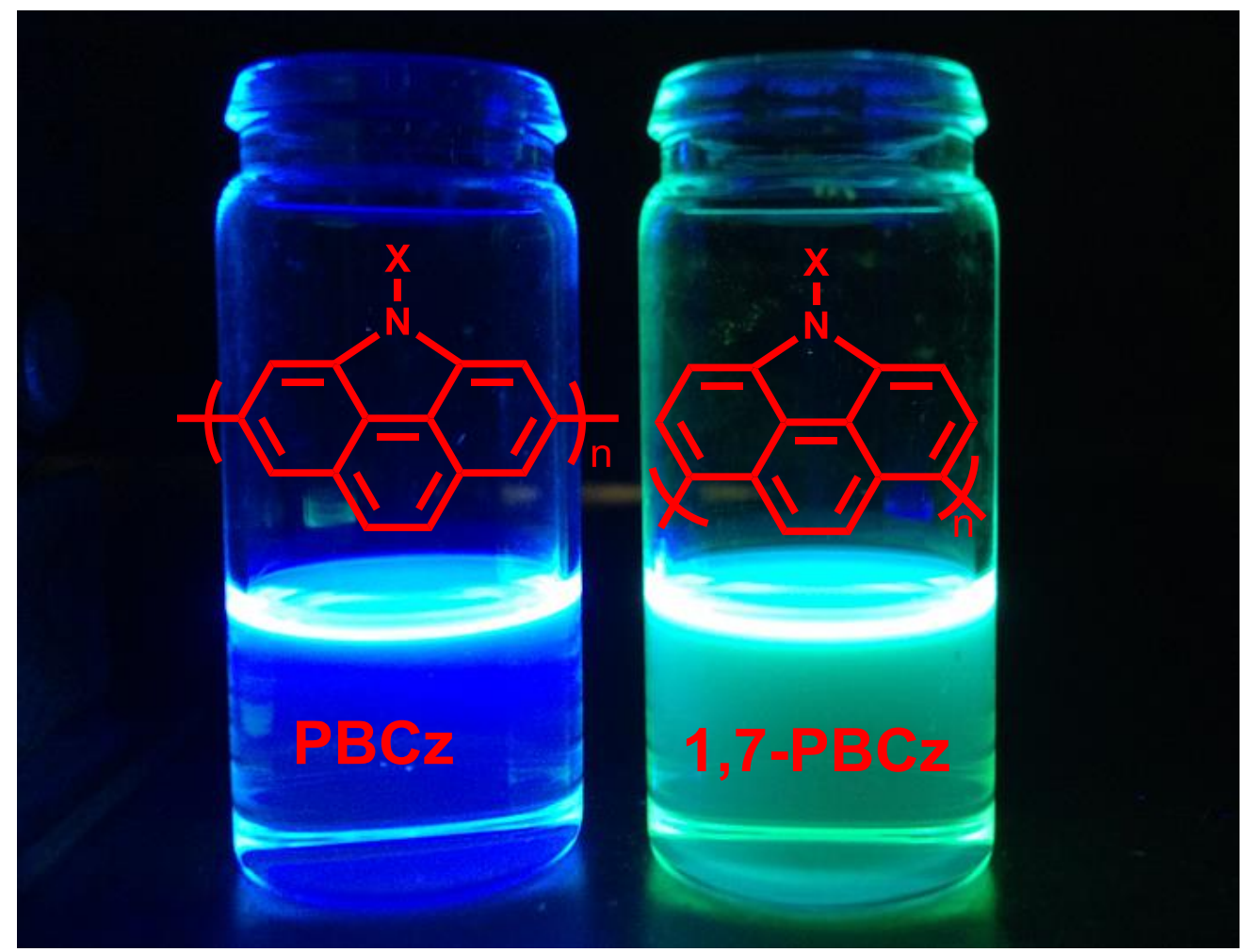

